\title{
AM I DRIVING OR ARE YOU OR ARE WE BOTH? A TAXONOMY FOR HANDOVER AND HANDBACK IN AUTOMATED DRIVING
}

\author{
Philipp Wintersberger ${ }^{1}$, Paul Green ${ }^{2}$, Andreas Riener ${ }^{1}$ \\ ${ }^{1}$ CARISSMA, University of Applied Sciences, Ingolstadt, Germany \\ ${ }^{2}$ University of Michigan Transportation Research Institute, Ann Arbor, USA \\ Email 1 firstname.lastname@thi.de; ${ }^{2}$ pagreen@umich.edu
}

\begin{abstract}
Summary: In this paper, a taxonomy of handover and handback (i.e., from manual to automatic control and vice versa) is proposed to be used by practitioners and researchers to help assure the duration of those periods are clearly defined, and accordingly, studies examining them are comparable and have repeatable results. Furthermore, use of this framework will help assure that those implementing automation will do so in a comprehensive manner. The taxonomy is more detailed than that in SAE Standard J3114.
\end{abstract}

Handover includes the phases preparation, perception (of the handover signal), suspension (of in-vehicle tasks) and the actual process of taking over, which can be subdivided into sufficient (to steer and control speed) and full (where situation awareness is complete) control. Furthermore, handover can be imminent, scheduled, or user-initiated. For handback, the phases are initialization, the actual handback, and re-engagement (of the driver). Handback may be optional or mandatory and user- or system initiated. For both handover and handback processes, the duration and change of the control transfer (as a function of time) needs to be precisely described/specified.

\section{INTRODUCTION}

With increasing vehicle automation, soon the point will be reached where (1) the automation, (2) a person, or (3) both driver and the automation will be alternately controlling the dynamic driving task (DDT). There will be periods when control is transferred from the driver to the automation and vice versa, which needs to be accomplished safely and comfortably. Interest in the parametrization of transition periods has led to "Take-Over-Requests" (TOR) or "handover" studies, mainly focusing on the (latest possible) time of manual handover of control in the direction automated towards manual driving. The motivation for handover studies is that when a situation arises beyond which the automation can handle (e.g., the edge lines have faded, the road path is uncertain, etc.), a human driver needs to resume control (what SAE J3016 refers to as DDT fallback), (Society of Automotive Engineers, 2016). Not receiving adequate attention are scheduled handovers during support of highway driving, an initial implementation. For that implementation, a (scheduled) shift of control will occur at least twice per trip (e.g., at expressway entrances and exits). Such scheduled transitions differ from imminent transitions, so the research questions may be different as well. The opposite side, i.e., when the vehicle is assumed to take back control is also of interest ("handback"). Just as the lack of consistency in the use of terms (so studies could be compared) necessitated the development of SAE Recommended Practice J2944 (Society of Automotive Engineers, 2015), so too here emerges the 
need for a framework, specifically a taxonomy, to support the comparison of studies. For example:

- A control transition might not have a sharp boundary between manual and automated driving but a gradual transition phase with varying extent (Flemisch, Schieben, Kelsch, \& Löper, 2008). In this situation, when has the handover occurred?

- Many studies define handover time as the reaction time needed for a physical reaction (braking, steering or pressing a button) in response to some external event. Few include the time needed to regain situation awareness, which is necessary to be truly in control.

- Studies often provide data on a minimum or mean handover time. However, from the safety perspective, the maximum or some distribution percentile may be the important value to be certain that a wide range of drivers in varying conditions have adequate time to respond.

- All of this occurs in the context of the primarily task workload, which is rarely quantified (Schweitzer \& Green, 2007).

This paper builds upon ideas in the literature. McCall et al. (2016) identified key characteristics of handovers, including scheduled, non-scheduled system initiated, non-scheduled user initiated and emergency (user or system initiated) handover situations, ideas included in the taxonomy are presented here. Lu and colleagues (2016) presented a taxonomy from a descriptive rather than a normative perspective, resulting in six different types of control transfer and further emphasize researchers to include types that are not directly safety related in future research. In addition, SAE J3114 (Society of Automotive Engineers, 2016) also describes different types of control transfer sequences (when exactly does a transition start/end, how to split the overall control transition in different sections) with phases "meaningful to the human". We argue that a taxonomy of control transfer phases should also address (1) the system/machine side as we speak of a "joint human-machine" system and (2) dual/sequential task considerations as automated driving promises to free the driver to perform additional activities. Those activities, related to entertainment, communication or productivity (Pfleging, Rang, \& Broy, 2016), may at least partly be supported by in-vehicle information systems (such as head-up-displays) that need to adapt to the current situation to allow fluent switching between the driving and other in-vehicle tasks.

\section{A TAXONOMY OF CONTROL TRANSITIONS}

Consideration of those ideas combined with the authors thinking leads to the two distinctive processes handover (Table 1) and handback (Table 2). Transitions from the automation to the driver have the uncertainty of placing potentially unaware human operators in charge of a safetycritical system. Transitions to the automation on the other hand raise ethical and legal issues, most prominently the questions (1) if the system is allowed to withdraw vehicle control without consent of the driver, and (2) how to justify such a decision. For both directions of transfer of control, questions of optimal notification times and resumption strategies emerge. Drivers could switch today's definitions of primary (driving) and secondary tasks (side activities) and thus may not accept automated systems that override what they want to do in non-critical situations. 


\section{Handover to the Driver}

There are three basic types of handover transitions - scheduled, imminent and driver-initiated transitions. Both scheduled and imminent transitions are initiated by the automation. Scheduled transitions have the advantage that the system knows about them in advance, allowing for better transition planning. In addition to SAE 3114 we define a preparation phase (following SAE 3114 Phase 1 "Event/Condition or System State Change") that allows to deal with non-critical, scheduled transitions and further split Phase 2 ("Request") into the three sections perception, suspension and sufficient TOR.

Table 1. Handover Taxonomy (SAE 3114 Phases on the bottom, additional phases on top)

\begin{tabular}{|c|c|c|c|c|c|c|c|}
\hline \multicolumn{2}{|c|}{$\begin{array}{l}\text { Transfer Control Sequence } \\
\text { AD to Manual Control }\end{array}$} & \multicolumn{2}{|c|}{ Request Issued } & & Take-Ove & \multirow{2}{*}{\multicolumn{2}{|c|}{ Response }} \\
\hline & & $\begin{array}{c}\text { Preparation } \\
\text { Scheduled TOR }\end{array}$ & Perception & Suspension & Sufficient TOR & & \\
\hline Cognitive & & & $\begin{array}{l}\text { Perceive Request } \\
\text { to Intervene }\end{array}$ & $\begin{array}{l}\text { Cognitive } \\
\text { Suspension of } \\
\text { Side Activity }\end{array}$ & Road Fixation & \multirow{3}{*}{ 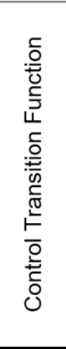 } & $\begin{array}{l}\text { Situation } \\
\text { Awareness }\end{array}$ \\
\hline Physical & & & & $\begin{array}{l}\text { Physical } \\
\text { Suspension of } \\
\text { Side Activity }\end{array}$ & $\begin{array}{l}\text { Hands on Wheel } \\
\text { Foot on Pedal }\end{array}$ & & $\begin{array}{l}\text { Longitudinal / } \\
\text { Lateral Vehicle } \\
\text { Stability }\end{array}$ \\
\hline System & $\begin{array}{l}\text { Detect Request to } \\
\text { Intervene }\end{array}$ & $\begin{array}{l}\text { Prepare Request } \\
\text { Driver State } \\
\text { Assessment, } \\
\text { Workload } \\
\text { Management }\end{array}$ & $\begin{array}{l}\text { Detect Request } \\
\text { Perception }\end{array}$ & $\begin{array}{l}\text { Adaption of } \\
\text { Interfaces \& } \\
\text { Information } \\
\text { Systems }\end{array}$ & $\begin{array}{l}\text { Detection of } \\
\text { Motor Readiness }\end{array}$ & & $\begin{array}{l}\text { Measure Driving } \\
\text { Performance and } \\
\text { Situation } \\
\text { Awareness }\end{array}$ \\
\hline PO & P1 & & \multicolumn{3}{|l|}{ P2 } & P3 & P4 \\
\hline
\end{tabular}

Preparation: What occurs in the Preparation Phase depends upon the implementation (Lu, et al. 2016). Is the transition stepwise? If a workload manager issues a Take-Over-Request, is it merely a suggestion, or at some time, does the automation shut off? How much warning is needed in each situation? What if the driver does not suspend a secondary task? The time frame must be long enough to allow a stress-free gain of situation awareness while being brief enough to be accepted (if the notification comes too early, the driver could ignore it and choose his own reference point). Most TOR studies start to measure reaction time in the Perception Phase when the system issues the request. For, multimodal notifications, which seem to be most effective (Politis, Brewster, \& Pollick, 2015), when does timing start if the stimuli are not simultaneous?

Suspension: As soon as the driver is aware of the upcoming transition, he/she must suspend the ongoing secondary task (Suspension Phase), if any, which includes cognitive (Martens \& van den Beukel, 2013) and physical processes. Although Zeeb et al. (2015) state that TOR is mostly influenced by cognitive rather than motor processes, higher levels of automation could show otherwise. Drivers might adjust their seat position (rotatable seats have been discussed) or perform more complex activities (eating, gaming, etc.) that require a longer physical suspension time, where some activities will prevent a gain of situation awareness until physical suspension is complete. Further, as some side activities will make use of in-vehicle interfaces and information systems, these also must adapt to the new conditions.

Handover: As soon as the secondary task is suspended, the Handover Phase begins, a phase split into Sufficient handover and Full handover. A sufficient handover is achieved as soon as the 
driver is physically able to drive (end of response time in most studies and start of the SAE 3114 "transfer" phase). Therefore, the overall handover ends with the full handover ("receipt \& recovery" as described in SAE J3114), when the driver has gained full situation awareness and driving fitness. Methods to determine the end of a full handover could be the investigation of scanning patterns including side- and rearview mirrors (Gold, Damböck, Lutz, \& Bengler, 2013) and/or observing small changes in lateral/longitudinal control to evaluate the stability of vehicle control.

\section{Handback to the System}

The transition from the driver to the automation (Handback) has not been topic of many studies so far and seems less complex (Table 2). According to Lu, et al. (2016), such transitions can be user initiated (optional and mandatory) or system initiated. Optional user initiated is any situation where the driver enables automation without immediate need.

Table 2. Handback Taxonomy (SAE 3114 Phases on the bottom, additional phases on top)

\begin{tabular}{|c|c|c|c|c|c|c|}
\hline \multicolumn{2}{|c|}{$\begin{array}{l}\text { Transfer Control Sequence } \\
\text { Manual to AD Control }\end{array}$} & $\begin{array}{l}\text { Automation } \\
\text { available }\end{array}$ & $\begin{array}{l}\text { nation } \\
\text { bled }\end{array}$ & $\begin{array}{l}\text { Automation } \\
\text { engaged }\end{array}$ & \multicolumn{2}{|c|}{$\begin{array}{c}\text { Full } \\
\text { Handback }\end{array}$} \\
\hline \multirow[b]{2}{*}{ Cognitive } & & \multicolumn{2}{|c|}{ Initialization } & & Handback & Reengagement \\
\hline & & $\begin{array}{l}\text { Decision to } \\
\text { Activate } \\
\text { Automation }\end{array}$ & & \multirow{3}{*}{ 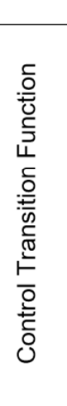 } & $\begin{array}{l}\text { Cognitive } \\
\text { Suspension of } \\
\text { Driving Task }\end{array}$ & $\begin{array}{l}\text { Cognitive } \\
\text { Reeingagement } \\
\text { in Secondary } \\
\text { Task }\end{array}$ \\
\hline \multirow{3}{*}{ System } & & $\begin{array}{l}\text { Enable } \\
\text { Automation }\end{array}$ & $\begin{array}{l}\text { Set Automation to } \\
\text { Active State }\end{array}$ & & $\begin{array}{l}\text { Physical } \\
\text { Suspension of } \\
\text { Driving Task }\end{array}$ & $\begin{array}{l}\text { Physical } \\
\text { Reeingagement } \\
\text { in Secondary } \\
\text { Task }\end{array}$ \\
\hline & $\begin{array}{l}\text { Detect Availability } \\
\text { of Automation }\end{array}$ & $\begin{array}{l}\text { Driver State } \\
\text { Assessment }\end{array}$ & $\begin{array}{l}\text { Detect Imminent } \\
\text { Need to Activate } \\
\text { Automation }\end{array}$ & & $\begin{array}{l}\text { Secondary Task } \\
\text { Suggestions, } \\
\text { Explanation of } \\
\text { Transition Reason }\end{array}$ & $\begin{array}{l}\text { Adaption of } \\
\text { Interface and In- } \\
\text { Vehicle } \\
\text { Information } \\
\text { System }\end{array}$ \\
\hline & $\mathrm{PO}$ & P1 & P2 & P3 & & \\
\hline
\end{tabular}

Mandatory user-initiated handbacks can become imminent if the driver experiences a critical situation, but the scenario of greatest concern is a system-initiated handback. Such handbacks could occur because of (1) a driver-related acute health risk (e.g., the driver is having a stroke or seizure) or (2) a massive decease of driving performance (e.g., the driver is identified as unacceptably fatigued, intoxicated, etc.), (3) the driver operates the vehicle in an aggressive, crash provocative manner, or (4) there is an imminent crash situation. Such paternalism from the system seems unlikely to be accepted by drivers. However, there could be situations where drivers have conditions that could necessitate having such features.

In the Initialization Phase of the handback process (spanning over the two SAE 3114 phases "automation available" and "decision to engage"), vehicle functions are manually enabled by the driver or automatically by the vehicle. As soon as the automation gains control over the driving functions (after the SAE 3114 "transfer" phase), the Handback Phase follows, where the driver is allowed to disengage from the function execution. In case of a system-initiated handback, the system must explain the reasons for the overruling or attempt to calm the driver should they react 
negatively to the system-initiated handback. Finally, in the Reengagement Phase, the driver is can start or continue with other side activities, supported by in-vehicle information systems.

\section{Control Transition Function}

Taking or releasing control from the system follows a Control Transition Function. In most studies so far, control immediately releases in the transfer phase. There could be situations where immediate transition is not appropriate (in the middle of a driving maneuver, etc.), so the transition could be gradual over time, or delayed. In addition, such functions could be different for handover/handback or lateral/longitudinal control. Future studies should evaluate different transition functions and durations. Questions would be, (1) how long should the time window be for a transition, (2) which transition functions (linear, exponential, ogival, etc.) provide the most stable and appropriately rapid transition for each situation, (3) should the functions for lateral and longitudinal control be the same, and (4) how do the answers to the proceeding questions differ for handover and handback?

\section{Context and Workload}

Quality and performance of control transitions are strongly influenced by context and workload. Road parameters such as road geometry, traffic (e.g., level of service) (Radlmayr, Gold, Lorenz, Farid, \& Bengler, 2014), surface conditions, sight distance will influence study results. So too do driver personality (age, gender, culture, experience, etc.), driver states and vehicle properties (manual or automated transmission, etc.).

\section{MEASUREMENT SUGGESTIONS}

To have clear definitions of the phases described in this taxonomy, their start- and endpoints need to be precisely identified. For that purpose, suggestions about how these phases could be measured (for the most common studies - unscheduled handback situations) are provided in Table 3. Current studies present handover reaction times ranging from in excess of one (Politis, Brewster, \& Pollick, 2015) to several seconds, where Radlmayr and Bengler (2015) state transitions of as much as 10 seconds is be suitable for most situations. For studies to be repeatable, measures must be consistently with the 1/5/75 Rule for pedal movements in SAE Recommended Practice J2944 (Society of Automotive Engineers, 2015). In that Rule, a 1\% change in some measurement of a pedal (e.g., pressure or travel) constitutes contact, a 5\% change in the same on which the foot is resting constitutes an overt response (e.g., releasing the accelerator, braking more aggressively), and $75 \%$ represents a maximal pedal application. Although not as explicitly defined, the presented practice uses $2 \%$ as an overt steering movement (Gold, Damböck, Lutz, \& Bengler, 2013). One of the lessons from the development of J2944 is that for many driving performance measurements, there is no single best definition, because the definition depends upon application of the measurement and the devices available to collect the data. Furthermore, the definitions of response time, mirrored to some degree in the proceeding table, suggest that there are multiple points in time at which handover and handback could be identified - initially, midway through the process, or at the end of some period. Thus, when defining transition periods, authors should include details concerning (1) the measurements, (2) 
durations in the different phases, (3) transition functions, and (4) the driving context. Suggestions for sufficient measurement endpoints for vehicle stability will be topic of future publications.

Table 3. Handover Measurement Suggestions

\begin{tabular}{|c|c|c|c|}
\hline Start of Notification & Sufficient Handover & Initial Response Time & Final Response Time \\
\hline $\begin{array}{l}\text { Hands free (Option A1) } \\
\text { Object in hand(s) (Option A2) }\end{array}$ & $\begin{array}{l}\text { Steering wheel grasped } \\
\text { Steering wheel moved }\left(2^{\circ}\right)\end{array}$ & Steering wheel touched & $\begin{array}{l}\text { Wheel enclosed with both } \\
\text { hands } \\
\text { Movement of } 2^{\circ} \text { detected }\end{array}$ \\
\hline $\begin{array}{l}\text { Foot on footwell (Option B1) } \\
\text { Undefined foot position } \\
\text { (recreational state, Option } \\
\text { B2) }\end{array}$ & $\begin{array}{l}\text { Brake pedal touched } \\
\text { Brake pedal pressed }(5 \%) \\
\text { Accelerator pedal touched } \\
\text { Accelerator Pedal pressed } \\
(5 \%)\end{array}$ & $\begin{array}{l}\text { - } \\
\text { Brake pedal touched } \\
\text { Accelerator pedal touched }\end{array}$ & $\begin{array}{l}\text { Brake pedal touched } \\
5 \% \text { Break value } \\
\text { Accelerator pedal touched } \\
5 \% \text { Accelerator value }\end{array}$ \\
\hline Start of Notification & Full Handover & Initial Response Time & Final Response Time \\
\hline $\begin{array}{l}\text { Glance on object/device used } \\
\text { in secondary task (Option C2) }\end{array}$ & $\begin{array}{l}\text { Glance on road } \\
\text { Glance on side mirror } \\
3 \text { point scanning }\end{array}$ & $\begin{array}{l}\text { Start of glance on } \\
\text { windshield } \\
\text { Start of glance on side } \\
\text { mirror } \\
\text { Start of glance on third } \\
\text { mirror }\end{array}$ & $\begin{array}{l}\text { End of glance on windshield } \\
\text { End of glance at side mirror } \\
\text { End of glance at third mirror }\end{array}$ \\
\hline Any start option from A-C & $\begin{array}{l}\text { Lateral stability } \\
\text { Longitudinal stability } \\
\text { Longitudinal stability }\end{array}$ & $\begin{array}{l}\text { Steering wheel moved }\left(2^{\circ}\right) \\
\text { Brake value } 5 \% \\
\text { Accelerator value } 5 \%\end{array}$ & TBD \\
\hline
\end{tabular}

\section{CONCLUSIONS}

The major point of this paper is that handover and handback are multi-phase and complex processes that need to be defined more precisely, specifically when each phase begins / ends. The authors would like to urge researchers and designers to consider the taxonomy presented in this paper (and SAE J3114) and use them to define what they mean by handover and handback and determine what to measure. Consideration of the taxonomy points to gaps in the literature that need immediate attention (how to quantify the complexity of the dynamic driving task, when is full situation awareness and vehicle stability achieved). It is hypothesized that at high levels of automation drivers and occupants will perform more complex side activities, increasing the importance of considering physical processes. Further, studies evaluating different Control Transition Functions for handover and handback as a function of driver workload are recommended.

\section{ACKNOWLEDGMENTS}

This work is supported under the Bavarian Funding Program for the Initiation of International Projects of the Bavarian Research Alliance (BayFOR) under grant agreement No. BayIntAn_THI_2016_155(PREVENTCRASH). 


\section{REFERENCES}

Flemisch, F., Schieben, A., Kelsch, J., \& Löper, C. (2008). Automation spectrum, inner/outer compatibility and other potentially useful human factors concepts for assistance and automation. Human Factors for Assistance and Automation.

Gold, C., Damböck, D., Lutz, L., \& Bengler, K. (2013). "Take Over!" How long does it take to get the driver back into the loop? Proc. of the Human Factors and Ergonomics Society Annual Meeting (S. 1938--1942). SAGE Publications.

Lu, Z., Happee, R., Cabrall, C. D., Kyriakidis, M., \& de Winter, J. C. (2016). Human factors of transitions in automated driving: A general framework and literature survey. Transportation Research Part F: Traffic Psychology and Behaviour, S. 183--198.

Martens, M., \& van den Beukel, A. (2013). The road to automated driving: dual mode and human factor considerations. ITSC 16th Int. IEEE Conference on Intelligent Transportation Systems. The Hague.

McCall, R., McGee, F., Meschtscherjakov, A., Louveton, N., \& Engel, T. (2016). Towards a Taxonomy of Autonomous Vehicle Handover Situations. Proc. of AutomotiveUI'16. Ann Arbor.

Pfleging, B., Rang, M., \& Broy, N. (2016). Investigating User Needs for Non-Driving-Related Activities During Automated Driving. Rovaniemi, Finland: 15th Int. Conference on Mobile and Ubiquitous Multimedia.

Politis, I., Brewster, S., \& Pollick, F. (2015). Language-based multimodal displays for the handover of control in autonomous cars. Proc. of AutomotiveUI'15 (S. 3--10). Nottingham: ACM.

Radlmayr, J., \& Bengler, K. (2015). Literature Survey and Description of Methods for the Development of Highly Automated Driving. FAT Schriftenreihe.

Radlmayr, J., Gold, C., Lorenz, L., Farid, M., \& Bengler, K. (2014). How traffic situations and non-driving related tasks affect the take-over quality in highly automated driving. Proc. of the Human Factors and Ergonomics Society Annual Meeting (S. 2063--2067). SAGE Publications.

Schweitzer, J., \& Green, P. A. (2007). Task acceptability and workload of driving urban roads, highways, and expressway: ratings from video clips. Ann Arbor, Michigan: University of Michigan Transportation Research Institute (UMTRI-2006-6).

Society of Automotive Engineers. (2015). SAE Surface Vehicle Recommended Practice Operational Definitions of Driving Performance Measures and Statistics. SAE Int.

Society of Automotive Engineers. (2016). SAE Surface Vehicle Information Report Human Factors Definitions for Automated Driving and Related Research Topics. SAE Int.

Society of Automotive Engineers. (2016). Taxonomy and Definitions for Terms Related to Driving Automation Systems for On-Road Motor Vehicles. SAE Int.

Zeeb, K., Buchner, A., \& Schrauf, M. (2015). What determines the take-over time? An integrated model approach of driver take-over after automated driving. Accident Analysis \& Prevention, S. 212--221. 